\title{
Current Trends and Practices Followed by Dental Technicians and Dentists in Fixed Crown and Bridges in India: A Cross-sectional Survey
}

Balendra Pratap Singh, Kamleshwar Singh, Nishi Singh, Kaushal Kishor Agrawal, Lakshya Kumar, Reema Kumari

\section{ABSTRACT}

Aim: To identify the current materials, design, communication and disinfection status followed by the dental laboratories in India regarding fixed prosthodontics.

Materials and methods: A prepiloted anonymous questionnaire containing 27 questions related to fixed prosthodontics was send to 472 laboratories in India. Information was obtained regarding procedure and materials for fixed prosthesis, die technique, accuracy of casts, design, communication, shade selection and disinfection practices followed by the laboratories. Questionnaire data were entered into a computer and analyzed using SPSS version 12.0 (SPSS, Inc, Chicago, IL, USA).

Results: Two hundred and sixteen of 472 dental laboratories responded (45.76\% response rate). Most common pontic design in both arches was ridge lap. One hundred and fifty-four $(71.29 \%)$ laboratories presented that most of the casts were not articulated. Majority of impression (66.20\%) received are not accurate enough for laboratories to do their best work. One hundred and eighty (82.8\%) laboratories have stated that less than $25 \%$ casts were disinfected. Most of the dentists $(65.74 \%)$ were not sending work authorization form and those who were sending are not complete enough $(63.42 \%)$.

Conclusion: The finding in this study indicated the weakness in technique and design of fixed prosthesis along with poor communication between dentists and laboratories in India.

Keywords: Quality, Fixed prosthodontics, Dental technicians, Impressions.

How to cite this article: Singh BP, Singh K, Singh N, Agrawal KK, Kumar L, Kumari R. Current Trends and Practices Followed by Dental Technicians and Dentists in Fixed Crown and Bridges in India: A Cross-sectional Survey. Int J Prosthodont Restor Dent 2013;3(2):43-49.

Source of support: Nil

Conflict of interest: None

\section{INTRODUCTION}

Prosthodontics is a demanding discipline with many clinical and laboratory procedures where a successful outcome depends on close cooperation between dentists and dental technicians.

Currently, 5,000 dental laboratories and 96 colleges for dental technicians are present in India. ${ }^{1}$ Three-fourth colleges are in private sector and rest in government sector educating 1,201 dental technicians/year. ${ }^{2}$ Ideal ratio of dental technicians to dentists should be 1:1 but it is around 1:4 in India which must be worsening due to exponential increase in dental colleges in India. ${ }^{3}$ Dental council of India provide license to work as dental laboratory technicians. There is no published literature to report current ratio of how many dentists have its own technicians but most of dental technicians work in owns laboratories/other laboratories/ have its own clinic.

With this background, dental laboratories can be an invaluable source of information regarding current trends in dental technology, problems and miscommunication between team members, and materials or techniques most often used. Such information can help us to assess the current level of quality in prosthesis fabrication and pinpoint the areas that need improvement. A number of dental laboratory surveys from different countries ${ }^{4-8}$ regarding fixed prosthodontics have been published. Regrettably, in spite of many published studies, only a few have been conducted during the last decade, a period of rapid development in dental materials and techniques and dental college/graduates. These studies were also focused on lack of communication between dentists and dental technicians on many issues, and, additionally, both overestimate the other's ability to correct mistakes without repeating certain procedures.

Prosthodontic practices have been done by qualified prosthodontist, dentists (maximum number of dental colleges in the world ${ }^{9}$ ) as well as quacks in the developing countries like India; ${ }^{10}$ so what quality of fixed prosthodontic patients are getting is need to be assessed. The few reasons behind the practice by quacks may be inadequate enforcement of the government, imbalance in geographical distribution of dentists, fewer chances of immediate complications, less awareness about the profession to public at large. ${ }^{11}$ This quality of prosthodontic practice can be assessed by fixed prosthodontic laboratories survey by using various factors, like designs of the prosthesis, materials used, fabrication procedures and cooperation between dentists and dental technicians.

So, the purpose of this study was to identify, through a survey of commercial dental laboratories in India, the current materials, technique, design and communication used for fabrication of fixed prosthesis.

\section{MATERIALS AND METHODS}

This study was conducted from April 2012 to October 2012. Ethical approval was taken from university ethical 
committee and conducted in full accordance with the World Medical Association Declaration of Helsinki. A selfadministered questionnaire consisting of 27 questions and separate five questions (Table 1) for intake of laboratories were designed to obtain information pertaining to:

- General question (Q. 1)

- Materials used (Q. 2-10)

- Design of fixed prosthodontics (Q. 11-17)

- Mounting (Q. 18-20)

- Shade selection/communication (Q. 21-27)

The questionnaire was pretested, revised and retested before use. At last of each section, there was a space for feedback by the dental laboratories. Questions of materials were related to materials used for impression, prosthesis and trey. Questions of design of prosthesis were related to pontic design, preparation of die, numbers of teeth replaced. Questions of mounting were related to use, type and setting of articulator. Questions of shade selection/communication were related to use of work authorization form, shade selection participation, glazing.

The questionnaire asked for anonymous responses to ensure confidentiality and overcome possible reservations about participation. It was accompanied by a cover letter stating the goals of the survey and it is advised to fill it by laboratory owner only.

The dental laboratories were selected from the list of dental laboratories of Indian Dental Association website. A list on the basis of alphabetical order of the laboratory name and having e-mail and contact address was prepared of every state despite its location, i.e. either from rural or urban. From this list of dental laboratories, every alternate laboratory was chosen to send the questionnaire either by mail or contact address. They could send the response by mail or by post (charges were prepaid). One month after the first mailing, a reminder was send for the reply. Out of 472 laboratories to whom questionnaire was send 216 (response rate: $45.76 \%$ ) responded. Questionnaire data were entered into a computer and analyzed using SPSS version 12.0 (SPSS, Inc, Chicago, IL, USA). The accuracy of input data was verified by entering the data twice and comparing the two subsequent datasets. No discrepancies were found in the data.

\section{RESULTS}

Four hundred and seventy-two questionnaires were distributed, of which 216 were complete and returned (response rate: $45.76 \%$ ). Most of the laboratory owner was diploma holder in dental mechanic (64.35\%) and have more than 5 years of laboratory experience. Almost half of the laboratories have inadequate employee and word load to laboratory owner was either very dissatisfied or dissatisfied in $44.8 \%$ laboratory (Table 1).
Table 1: Questions for intake of laboratories

\begin{tabular}{|c|c|c|c|}
\hline S. no. & Question & $n$ & $\%$ \\
\hline \multirow[t]{4}{*}{1.} & Qualification of owner of the laboratory & & \\
\hline & Diploma & 139 & 64.35 \\
\hline & Graduate & 19 & 8.79 \\
\hline & Postgraduate & 58 & 26.85 \\
\hline \multirow[t]{4}{*}{2.} & $\begin{array}{l}\text { Experience as dental mechanic/dental } \\
\text { hygienist (years) }\end{array}$ & & \\
\hline & $<1$ & 20 & 9.25 \\
\hline & $2-5$ & 17 & 7.87 \\
\hline & $>5$ & 179 & 82.87 \\
\hline \multirow[t]{6}{*}{3.} & Work load & & \\
\hline & Very dissatisfied & 33 & 15.27 \\
\hline & Dissatisfied & 64 & 29.62 \\
\hline & Neutral & 29 & 13.42 \\
\hline & Satisfied & 90 & 41.66 \\
\hline & Very satisfied & 0 & 0 \\
\hline \multirow[t]{4}{*}{4.} & $\begin{array}{l}\text { How much time (in hours) you give to your } \\
\text { laboratory in a week }\end{array}$ & & \\
\hline & Upto 48 (adequate) & 49 & 22.68 \\
\hline & 49-60 (fair) & 64 & 29.62 \\
\hline & 61-72 (inadequate) & 103 & 47.68 \\
\hline \multirow[t]{4}{*}{5.} & $\begin{array}{l}\text { How many employees are present in your } \\
\text { laboratory for fixed prosthodontics work }\end{array}$ & & \\
\hline & Adequate & 22 & 10.18 \\
\hline & Fair & 76 & 35.18 \\
\hline & Inadequate & 118 & 54.62 \\
\hline
\end{tabular}

A total of $90 \%$ of the laboratories have more than $50 \%$ of work related to fixed prosthodontics in nature (Table 2).

Dentists were most commonly using porcelain fused metal (PFM) (90.27\%) and base metal alloys (89.35\%) as crown and bridge materials. Majority of crown and bridge impression were made with full arch custom tray (66.66) using alginate (88.42\%) (Table 2).

Majority of impression $(66.20 \%)$ received are not accurate enough for laboratories to do their best work. Dentists were commonly using die stone $(54.62 \%)$ but very few were using die pin $(67.59 \%)$. A total of $180(82.8 \%)$ laboratories have stated that less than $25 \%$ casts were disinfected (Table 2).

Near half of the dentists were replacing more than four maxillary and mandibular anterior teeth (44.44 and 55.55\% respectively) (Table 3). Many times dentists send the bridge preparation which was not obeying Ante's law (56.48\%). Most commonly pontic design in maxillary (81.48\%) and mandibular (79.16\%) bridge was ridge lap (Table 3).

A total of $71.29 \%$ fixed crown and bridge cases were not articulated and those which were articulated is mainly done by laboratory personnel (73.61\%) on instruction of dentists or laboratory itself (Table 3).

Majority of dentists were not sending work authorization form $(65.74 \%)$ and those were sending are not complete enough (63.42\%). Majority of dentists did not write about pontic design $(55.09 \%)$ and also not participating in shade selection $(58.79 \%)$ (Table 4$)$. 
Table 2: General question, material and techniques being used

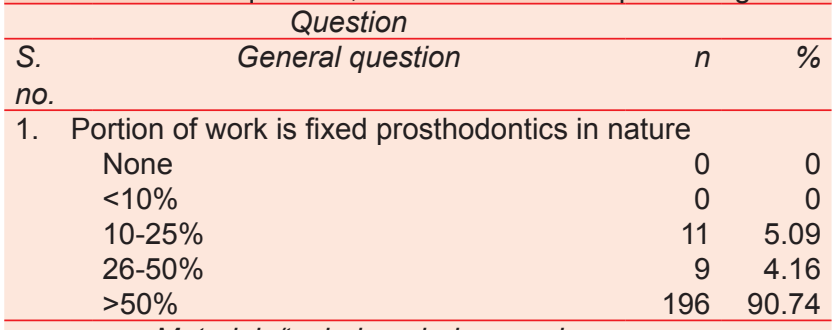

\section{Materials/technique being used}

2. What portions of the final impressions received by your laboratory have been poured by the dentist?

$\begin{array}{lll}<25 \% & 46 & 21.29 \\ 25-50 \% & 38 & 17.59 \\ 51-75 \% & 67 & 31.01 \\ 76-100 \% & 65 & 30.09\end{array}$

3. Most commonly used material in fixed crown and bridge?

PFM

All acrylic

Metal acrylic

0

All ceramic

21

All metal

4. Portion of your crown and bridge restorations are made with alloys containing gold?

$\begin{array}{lrr}<25 \% & 193 & 89.35 \\ 26-50 \% & 13 & 6.01 \\ 51-75 \% & 10 & 4.62 \\ 76-100 \% & 0 & 0\end{array}$

5. Majority of the crown and bridge final impressions in your laboratory are made with

Full arch custom tray

Full arch stock tray

Half arch custom tray

Half arch stock tray

Other

6. What portion of the master casts and/or final impressions received by your laboratory are accurate enough for you to do your best work in making the restoration

Less than $25 \%$

$26-50 \%$

$51-75 \%$

$76-100 \%$

7. How many cast have used die stone?

Less than $25 \%$

$26-50 \%$

$51-75 \%$

$76-100 \%$

$23 \quad 10.64$

$147 \quad 66.66$

$19 \quad 8.74$

$27 \quad 12.5$

$0 \quad 0$

8. How many cast have used die pin?

Less than $25 \%$

$26-50 \%$

$51-75 \%$

$76-100 \%$

9. Most commonly used impression material by

the dentists

Alginate

Polyether

Addition silicone

Others

10. How many master impression/cast been disinfected adequately by the dentists?

Please comment how do you know it has not been disinfected adequately?

\begin{tabular}{lrr}
$<25 \%$ & 180 & 83.33 \\
$26-50 \%$ & 15 & 6.94 \\
$51-75 \%$ & 15 & 6.94 \\
$76-100 \%$ & 10 & 4.62 \\
\hline
\end{tabular}

14.86

6.01

6.94
Table 3: Design of fixed prosthesis and mounting an articulator

S. Design of fixed prosthesis $n \quad \%$

no.

11. The majority of PFM restorations completed by your laboratory have

A facial collar of metal $\quad 9 \quad 4.16$

Porcelain carried all the way down to the $\quad 197 \quad 91.20$

facial margin

Other

$0 \quad 0$

12. Maxillary anterior teeth $(>4)$ were replaced

among maxillary anterior bridge

Less than $25 \%$

$26-50 \%$

$51-75 \%$

$76-100 \%$

$36 \quad 16.66$

$84 \quad 38.88$

$96 \quad 44.44$

13. Mandibular anterior teeth (>4) replaced among mandibular anterior bridge

Less than $25 \%$

$26-50 \%$

$51-75 \%$

$76-100 \%$

0

0

4. How many times posterior teeth you replaced

not obeying Ante's law with reference to

natural dentition?

Less than $25 \% \quad 38 \quad 17.59$

$26-50 \% \quad 50 \quad 23.14$

$\begin{array}{lrr}51-75 \% & 122 & 56.48\end{array}$

$\begin{array}{lll}76-100 \% & 6 & 2.77\end{array}$

15. Types of posterior pontics found most commonly

Ovate

$0 \quad 0$

Sanitary $\quad 40 \quad 18.51$

Ridge lap $\quad 171 \quad 79.16$

$\begin{array}{lll}\text { Modified ridge lap } & 5 & 2.31\end{array}$

Other

31
0

16. What portion of the dies has been trimmed by

the dentists?

Less than $25 \% \quad 178 \quad 82.40$

$26-50 \% \quad 13 \quad 6.01$

$51-75 \% \quad 13 \quad 6.01$

$76-100 \% \quad 12 \quad 5.55$

17. Types of anterior pontics found most commonly Ovate

Sanitary

Ridge lap

4.16

Modified ridge lap

0

81.48
14.35

Other

0

18. Crown and bridge are mounted on

Semiadjustable or adjustable articulator $\quad 13 \quad 6.01$

Plane line or hinge type articulator with $\quad 23 \quad 10.64$

lateral movement capacity

Plane line or hinge type articulator

without lateral movement capacity

Not articulated

12.03

19. Cases mounted on a semiadjustable/

adjustable articulator, the majority of the

instrument settings are

Set by the dentist

Set by laboratory

$34 \quad 15.740$

Set to average values

62.96

Other

4.62

20. Portion of the crown and bridge cases received and mounted on an articulator by the dentist?

Less than $25 \%$

$26-50 \%$

$51-75 \%$

$76-100 \%$

12

$13 \quad 6.01$ 
Table 4: Shade selection/communication

S. Shade selection/communication

n $\%$

no.

21. How many dentists send work authorization/ prescription form to your laboratory?

$\begin{array}{lrr}<25 \% & 142 & 65.74 \\ 25-50 \% & 39 & 18.05 \\ 51-75 \% & 21 & 9.72 \\ 76-100 \% & 14 & 6.48\end{array}$

22. Portions of the PFM restorations fabricated and returned to the dentist prior to porcelain application for a coping try-in?

Less than $25 \%$

$178 \quad 82.40$

$26-50 \%$

$51-75 \%$

$76-100 \%$

$24 \quad 11.11$

$14 \quad 6.48$

$0 \quad 0$

23. Portions of the PFM restorations completed and returned to the dentist unglazed for final contour modifications or custom characterization?

Less than $25 \%$

16576.38

$26-50 \%$

$51-75 \%$

$76-100 \%$

$76-100 \%$

24. What portion of your crown and bridge work authorizations or prescriptions indicate the specific type of alloy to be used?

$<25 \%$

$26-50 \%$

$51-75 \%$

$76-100 \%$

$145 \quad 67.12$

$9 \quad 4.16$

$62 \quad 28.70$

$0 \quad 0$

25. Portion of your clients request you to participate in shade selection and/or custom characterization of porcelain restoration at your laboratory?

Less than $25 \%$

$137 \quad 58.79$

$26-50 \%$

$24 \quad 11.11$

$51-75 \%$

$76-100 \%$

3214.81

$23 \quad 10.64$

26. How many prescription indicate about pontic design

Less than $25 \%$

$26-50 \%$

$51-75 \%$

$76-100 \%$

11955.09

$38 \quad 17.59$

$46 \quad 21.29$

$13 \quad 6.01$

27. Please tick the appropriate statement, the written instructions are:

Clear, and adequately describe the planned fixed partial denture prosthesis

A guide and some of the design is left to the technician

Poor, and most of the design is left to the technician

There are no written instructions

\section{DISCUSSION}

Fixed prosthodontics work involved several steps with great cooperation and communication between dentists and laboratories technicians. Managing work done by one partner will affect quality of work done by another because minor/major fault at any steps need time as well as effort. So, to assess status of quality of fixed prosthodontic work, laboratory survey is best possible way to judge.

There were few surveys regarding fixed prosthodontic laboratory status and quality of prosthesis and they recommended such more studies in other parts of the world to gain a realistic global sense of the procedures occurring in daily clinical and laboratory dental practice. In India, fixed prosthodontic practices is being carried out by wide variety of professionals, including postgraduate dentists, graduate dentists and quacks (nonqualified dentists including dental technicians, hygienist, road side persons). India is now have maximum number of dental college in the world and dentists workforce will become 225,000 shortly. ${ }^{9}$ Quacks are almost five to six times of dentists' practices in India. So, it is again very important to assess the fixed prosthodontics laboratories status in India.

The findings of this investigation were quite revealing as to the attitudes and habits of dental practitioners in India in the field of fixed prosthodontics.

Response rate was $45.76 \%$ which was similar to rates found in the published literature. Dental laboratories appreciated this effort because they feel that it raised issues related to the laboratory. Possible reasons of not responding might be lengthy questionnaire and/or neglect.

Major portion of work ( $>50 \%$ ) was fixed prosthodontics in nature in $90.7 \%$ of laboratories. Other literature also showed almost similar percentage. ${ }^{12,13}$

A total of $21.2 \%$ laboratories stated that less than 25\% impressions were poured by dentists. This part is again very important because $88.4 \%$ dentists used alginate as impression materials. The laboratory personal in their feed back form stated that it was poured by nonqualified person (not dental technicians/hygienists) working in the clinic or send from laboratory to collect working cast. This was happened probably due to financial reasons, attitude or dentist may thought that if he/she hired dental hygienist/ technicians in the clinic then they might learn the work and start doing practice next to his/her clinic.

Porcelain fused to metal was most commonly used material in crown and bridge which was similar to other studies. ${ }^{8,14}$ Fabrication of metal acrylic restoration was quite high despite the inherent disadvantages of acrylic veneers. ${ }^{15}$ Feedback form indicated the reasons behind that were lower cost and easy repair than porcelain. A total of $89.35 \%$ laboratory stated that less than $25 \%$ alloy used in fixed prosthesis was gold alloy. The published literatures showed low percentage of use of base metal alloys in other part of the world. ${ }^{16-18}$ 
Majority of crown and bridge final impressions were made with full arch stock trey. ${ }^{19-21}$ Half arch impression may create technical difficulties because of lack of stability during mounting procedure. Impression received by laboratory was regarded as inadequate by most of the dental technicians. This step is completely depending on dentists. Inaccurate impressions have been raised major problems in published surveys. ${ }^{16,22}$

The percentage also remained high in surveys where dentists had performed the quality check. ${ }^{6,723}$ Feedback form stated that there was majority of reasons, such as unclear margin, voids and drags. It was also mentioned by laboratories that poor quality of impression might be due to low quality materials used by dentists. Similar comments have been in previous surveys. ${ }^{17,24}$ Only $12.5 \%$ laboratories observed that their master cast was made up of die stone and in only $6.15 \%$ of laboratories cast had die pin. This was important finding because in feedback form laboratories owner had written that frequent repetition of the cases was done due to complain of high occlusion or nonseating of prosthesis. Due to not using die stone (dental stone instead) chances of abrading the surface of prepared tooth and adjacent tooth along with opposing tooth occurred leading to high occlusion and inaccuracy. Without die pin, separation of die was not possible and chances of adequate proximal contact and marginal adaptation cannot be achieved leading to frequent and early complication of tooth supported fixed partial denture.

In only $15 \%$ laboratories, all the cast were disinfected. This was identified by the laboratories due to presence of blood stain and food particles on the nondisinfected cast. This status may lead to potentially vulnerable infectious disease from impression and other items in dental laboratories to technicians. ${ }^{25,26}$ Therefore, a proper disinfection protocol should be adhered to by the dentists and technicians. In feedback form, only $15 \%$ laboratories was regularly disinfecting all the incoming items.

Most common anterior and posterior pontic fabricated by laboratories were ridge lap despite its disadvantages of food lodgment leading to caries and loss of abutment. Laboratory technicians have commented that dentists ordered such type of pontic because of esthetics. The frequent use of such pontic design may be because of not using work authorization form in every case, unqualified dentists and laboratories technicians, less awareness among patients and no enforcement of law agencies. These reasons may also be related to frequently replacing more than four anterior teeth in maxillary and mandibular arch; replacing posterior teeth not obeying Ante's law with reference to natural dentition. A total of $7 \%$ cases received at laboratories were not articulated at all. In other survey, this percentage was quite less. ${ }^{16}$ It is another big area of concern for the indirect simulation of dynamic maxillomandibular relationships.

As noted, $65.7 \%$ dentists did not send work authorization form to laboratories and among those who send; only $4.62 \%$ authorization form quality is clear and adequately described the planned prosthesis. This was evident by the fact that only $6 \%$ dentists written about pontic design, no dentist commented on specific type of material to be used regarding alloy. Poor communication was also found in relation to coping try-in (less than $25 \%$ restoration in $82.4 \%$ laboratories) and glazing after final modification. Other laboratory surveys had founded similar result but percentage was better. ${ }^{27-29}$ Only $10.6 \%$ dentists requested the dental technicians to participate in shade selection. This percentage is quite less than in other surveys. ${ }^{8}$ In the feedback form, dental technicians had mentioned that most of the time one shade tab identification was orally communicated (not written) to laboratories by dentists which compounding the potential of error.

It is disappointing that even though the problems of inadequate prescription and communication between clinicians and laboratories was first highlighted almost 30 years ago,${ }^{30}$ There is still evidence that these problem still exist. The reasons for this are not entirely clear. Possible reasons in fixed prosthodontics included a lack of adequate educational exposure ${ }^{31}$ or inadequate financial remuneration. ${ }^{23}$

As these laboratory run on private basis so depending on the case dentists as well can charge the fee as per case, so inadequacy of financial reasons is not clear. The problem may lie in the education exposure/continuing dental education of dentist, dental technicians, guideline for dental society of dentist and dental technicians (in India no association for dental technician exist and only one dental technicians journal was started four years back), law enforcing the practicing by quacks, mass awareness of public.

The majority of dental technicians expressed that the time for delivery requested by the dentist was insufficient for quality work to be produced. ${ }^{24}$ This issue need to tackle by dental community because time pressure may result in neglect and poor quality work. This was further emphasized by feedback form, which implied that major portion of dentists consider time to be a more important factor than quality. It is quite disturbing that in an era of prosthodontics in which sophisticated technology, bioengineering and advanced basic science research are being implemented, clinical and laboratory procedures in daily practice do not even comply with basic protocols taught in dental school. However, such studies can help the profession realize the reasons why patients are not enjoying the full benefits that prosthetic dentistry can provide. 


\section{CONCLUSION}

Within the limitation of this study, majority of impression received by the laboratories are not accurate enough and communication between dentists and laboratories is poor. Impressions/casts are not disinfected and design of the prosthesis was not following the norm as was studied by the dentists. This showed the need by the general public for the quality prosthodontic treatment despite increase in number of dentists in India. Further investigations are warranted to determine the method to manage quality treatment for the population at large.

\section{REFERENCES}

1. Tandon S. Challenges to the oral health workforce in India. J Dent Educat 2004;68:28-33.

2. Dentistry potential. Available at: http://www.delhidentalshow. org.in/textpages/newtextpages/futureofdentistryindia.aspx. Accessed on: 2013 September 24.

3. Dental Council of India. List of the institution approved/ recognized by the DCI to run the dental mechanics \& dental hygienists courses. Available at: http://www.dciindia.org/ dental_hygienists_pages/web\%20site $\% 201$ ist $\% 20$ of $\% 20$ DM\%20and\%20DH.pdf. Accessed on: 2013 September 25.

4. Williams GJ, Edmunds DH. Crown and bridge technology in the United Kingdom. A survey of dental laboratories. Br Dent J 1981;150:215-217.

5. MacEntee MI, Belser UC. Fixed restorations produced by commercial dental laboratories in Vancouver and Geneva. J Oral Rehabil 1988;15:301-305.

6. Winstanley RB, Carrotte PV, Johnson A. The quality of impressions for crowns and bridges received at commercial dental laboratories. Br Dent J 1997;183:209-213.

7. Albashaireh ZS, Alnegrish AS. Assessing the quality of clinical procedures and technical standards of dental laboratories in fixed partial denture therapy. Int J Prosthodont 1999;12:236-241.

8. Hatzikyriakos A, Petridis HP, Tsiggos N, Sakelariou S. Considerations for services from dental technicians in fabrication of fixed prostheses: a survey of commercial dental laboratories in Thessaloniki, Greece. J Prosthet Dent 2006;96:362-366.

9. Sivapathasundharam B. Dental education in India. Indian J Dent Res 2007;18:93.

10. Times online. 'India urged to train its quacks to solve shortage of doctors'. Available at: http://www.timesonline.co.uk/tol/news/ world/asia/article4036187.ece. Accessed on: 2008 May 31.

11. Jain H, Agarwal A. Current scenario and crisis facing dental college graduates in India. J Clin Diagn Res 2012;6:1-4.

12. Baumann B, Pai WH, Bennani V, Waddell JN. Dental alloys used for crown and bridge restorations by dental technicians in New Zealand. N Z Dent J 2010;106:43-49.

13. Afsharzand Z, Rashedi B, Petropoulos VC. Dentist communication with the dental laboratory for prosthodontic treatment using implants. J Prosthodont 2006;15:202-207.

14. Stankiewicz NR, Wilson PR. A survey of the distribution and types of full crowns prescribed in Melbourne, Australia. Aust Dent J 2000;45:193-197.
15. Palmqvist $S$, Swartz B. Artificial crown and fixed partial dentures 18 to 23 years after placement. Int J Prosthodont 1993;6:279-285.

16. Aquilino SA, Taylor TD. Prosthodontic laboratory and curriculum survey. Part 3: fixed prosthodontic laboratory survey. J Prosthet Dent 1984;52:879-885.

17. MacEntee MI. Belser UC. Fixed restorations produced by commercial dental laboratories in Vancouver and Geneva. J Oral Rehabil 1988;15:301-305.

18. Olin PS, Clay DJ, Look JG. Current prosthodontic practice: a dental laboratory survey. J Prosthet Dent 1989;61:742-745.

19. Thongthammachat S, Moore BK, Barco MT 2nd, Hovijitra S, Brown DT, Andres CJ. Dimensional accuracy of dental casts: influence of tray material, impression material, and time. J Prosthodont 2002;11:98-108.

20. Damodara EK, Litaker MS, Rahemtulla F, McCracken MS. A randomized clinical trial to compare diagnostic casts made using plastic and metal trays. J Prosthet Dent 2010 Dec;104(6):364-371.

21. Reddy JM, Prashanti E, Kumar GV, Suresh Sajjan MC, Mathew $\mathrm{X}$. A comparative study of inter-abutment distance of dies made from full arch dual-arch impression trays with those made from full arch stock trays: an in vitro study. Indian J Dent Res 2009;20:412-417.

22. Kugel G, Perry RD, Ferrari M, Lalicata P. Disinfection and communication practices: a survey of US. dental laboratories. J Am Dent Assoc 2000;131:786-792.

23. Carrotte PV, Winstanley RB, Green JR. A study of the quality of impressions for anterior crowns received at a commercial laboratory. Br Dent J 1993;174:235-240.

24. Leith R, Lowry L, O'Sullivan M. Communication between dentists and laboratory technicians. J Ir Dent Assoc 2000;46:5-10.

25. Powell GL, Runnellls RD, Saxon BA, Whisenant BK. The presence and identification of organisms transmitted to dental laboratories. J Prosthet Dent 1990;64:235-237.

26. Owen CP, Goolam R. Disinfection of impression materials to prevent viral cross-contamination: a review and a protocol. Int J Prothodont 1993;6:480-494.

27. St Arnault FD, Evans PR. Dental laboratory work authorization forms: a national survey of regulatory agency requirements. J Prosthet Dent 1991;65:592-596.

28. St Arnault FD, Allen DL Jr. Dental laboratory work authorization forms: a survey. J Prosthet Dent 1990;64:497-501.

29. Petridis HP. An example of hierarchy of evidence vs hierarchy of information. Int J Prosthodont 2006;19:134-135.

30. Owall B. Design of removable partial dentures and dental technician education. Swed Dent J 1974;67:21-32.

31. Leeper SH. Dentist and laboratory: a 'love-hate' relationship. Dent Clin North Am 1979;23:87-99.

\section{ABOUT THE AUTHORS}

\section{Balendra Pratap Singh (Corresponding Author)}

Assistant Professor, Department of Prosthodontics, King George's Medical University, Lucknow, Uttar Pradesh, India, Phone: 05222257245, e-mail: balendra02@yahoo.com

\section{Kamleshwar Singh}

Assistant Professor, Department of Prosthodontics, King George's Medical University, Lucknow, Uttar Pradesh, India 


\section{Nishi Singh}

Senior Lecturer, Department of Conservative Dentistry and Endodontics, Chandra Dental College, Lucknow, Uttar Pradesh India

\section{Kaushal Kishor Agrawal}

Assistant Professor, Department of Prosthodontics, King George's Medical University, Lucknow, Uttar Pradesh, India

\section{Lakshya Kumar}

Assistant Professor, Department of Prosthodontics, King George's Medical University, Lucknow, Uttar Pradesh, India

\section{Reema Kumari}

Associate Professor, Department of Community Medicine and Public Health, King George's Medical University, Lucknow, Uttar Pradesh India 